\title{
How to Stop Chinglish
}

\author{
Weixiang Liu and Li Li \\ Science and Technology Institute of Nanchang University
}

Keywords: Chinglish; Language transfer; Writing; Causes; Countermeasures

\begin{abstract}
Chinglish is a pragmalinguistic failure caused by the interference of Chinese, culture and thinking mode and the similar condition is that English students use the wrong in Chinese writing. The research finds out that Chinglish is common in English writing. This paper combines language transfer, comparison, and error analysis to analyze the reason of pragmalinguistic failure and appearance of Chinglish as well as the characteristics and causes of Chinese-style vocabulary, syntax and discourse structure so as to come up with relative writing teaching strategies. Furthermore, this paper expects to provide references for relative teaching practices in order to correct and reduce the errors to finally improve writing skills.
\end{abstract}

\section{Introduction}

With the expansion of international exchange and cooperation, sky rocketing people clearly recognize the fact that Chinglish will affect the realization of effective intercultural communication. At present, a widely recognized theory and reference definition on Chinglish adopted by Chinese and foreign scholars is that Chinglish refers to spoken or written English language that is macaronically influenced by the Chinese language, which mechanically applies Chinese rules and habits,which does not accord with English culture. Chinese and English belong to different language families, which have obvious differences in terms of speech, social cultural background and habits of thoughts. Therefore, when Chinese study English, there will be interlanguage variation under the influence of Chinese and Chinese culture which is transient phenomenon which will inevitably happen.

Chinglish is a common problem in Chinese students' English writing, which is also an important problem in study of second language acquisition. While studying on the emergence and causes of Chinglish we have to combine three aspects, among which language transfer is a stage of error analysis which mainly analyzes the result caused by native language transfer or interference. This paper will fully reveal the characteristics and causes of Chinese-style vocabulary, syntax and discourse structure from the perceptive of language transfer, comparison, and error analysis theory to further come up with relevant teaching policies, hoping to bring along with inspiration and help for English writing in Universities.

\section{Causes for Chinglish}

Chinese Negative Transfer. Native language transfer refers to the effect on the second language or foreign language learning caused by the native language, which can be dived into negative and positive transfer. Positive transfer refers to the condition that the formation of the target language and native language is similar which is beneficial to the language learning transfer while negative transfer refers to opposite condition while the native language will interfere with the target language learning.

Unfamiliar With the Differences of Chinese and Western Culture and Thinking Ways. Chinese people tend to think about the whole, emphasize on ideas rather than logic. However, western culture is totally opposite, which advocates all or nothing, highlighting individual thinking, logic and rationality, praising highly the individual as well as structure formation rather than the whole. We can say that the logic analysis idea of western people is dead beat while Chinese people is auger-style with implicit expression. 
Different Pronunciation of Chinese and English. From the prestige of phonetics, the points of articulation can be divided into three parts: pharyngeal cavity, nasal cavity and mouth cavity while the production part and approaches of Chinese and English are different, which cause the difficulties for Chinese people to speak English. Chinese people say single intonation, cannot clear heavy and light syllables, find it difficult to have sound-linking. What's more, they are confused with dialects with obvious Chinese features.

\section{Presentation of Chinglish in Writing}

Cluster: If you volunteer to be a salesman, you can improve the skill of talking with strangers, you might become more confident and outgoing. Cluster has more than two independent sentences (usually simple sentences), which are divided by comma or linked with a adverb. This sentence can be changed like this: If you volunteer to be a salesman, you can improve the skill of talking with strangers, and become more confident and outgoing.

Lack of subject: I believe that if everyone takes a little step will make a great difference, this is translated based on the Chinese sentence 我相信如果每人都做出一点努力, 就会产生很大的影 响, which should be written like this: I believe that it will make a great difference if everyone takes a little step.

Redundant topics: Volunteer work, it' s good for people who need help and also the volunteers them-selves, which is translated based on the Chinese 志愿者工作, 它对需要帮助的人和志愿者 本人都有好处 while students translate word for word, which should be written like this: Volunteer work is good for people who need help and also the volunteers themselves.

Subject-verb disagreement: Volunteer work enrich the volunteer' $\mathrm{s}$ life and experience. In Chinese, the predicate verb will not change because of the changes of person, tense, and voice. In this sentence, enrich should be enriches.

\section{Solutions for Chinglish}

Pronunciation Solution. Scientists hold the idea that people are able to make a lot of sounds. That is to say, it is possible for English learners to pronounce the same sound like those native English speakers. The thing is while born in certain language environment, they are affected and their pronunciation is more and more inclined to this kind of language and it is difficult to pronounce other sounds. Thus we can see the importance of language environment. As non-English major university students, they should have more exposure to English sea s to copy and apply English. Only in constant practice, can they fix the problem and make a progress.

Solution for Negative Transfer While Learning English. Most of people are afraid of speaking English and they won't learn relative stuff after class or they will even lay aside the English books and ignore them. The author always encourage non-English major students to read more English articles, watch English movies, dramas, and listen to English music etc after class time. If students find it difficult, they can read some simple articles to build confidence first.

Solutions for Cultural Understanding. During the teaching process, we can introduce the comparison of English and Chinese language, culture and thinking mode so as to help students understand the differences, especially the language differences and thinking mode differences in vocabulary application, syntactic stricture, and discourse structure. What's more, we have to focus on cultivating students' awareness of intercultural writing to inspire students find out the different cultural connotation of vocabulary and phrase. Furthermore, we can also use typical syntactic structures, short articles in Chinese and English to carry out comparison and correction based on translation and special writings. Based on this, we can strengthen students' understanding on Chinese and English language, culture and thinking mode, help them to realize the fact that English focuses on hypotaxis while Chinese highlights parataxis to gradually improve their English thinking ability. 


\section{Conclusion}

Before accurately mastering and being proficient in English writing, Chinglish is inevitable, which commonly exists in writing, mainly showing in vocabulary, syntax and discourse structure. Based on the classification and summary of the above three aspects as well as the study on language transfer, comparison and correction analysis theory, we can find out that the main causes of Chinglish are negative transfer of Chinese and different language rules as well as thinking mode. Therefore, except from strengthening the basic training in terms of vocabulary, sentence, paragraphs and articles, we have to strengthen the comparative teaching, talking about the language rules as well as the culture and thinking mode so as to guide students overcome the negative effect, avoid Chinglish. Furthermore, we should also cultivate their English thinking ability which can help them effectively carry out intercultural communication in work and social interaction.

\section{References}

[1] Sauro S. Chapelle, C. (2003). English language learning and technology: Lectures on applied linguistics in the age of information and communication technology [J]. Studies in Second Language Acquisition, 2005, 27(03):486-487.

[2] HuiYin Hsu, ShiangKwei Wang, Linda Comac. Using audioblogs to assist English-language learning: an investigation into student perception [J]. Computer Assisted Language Learning, 2008, 21(2):181-198.

[3] Zorko V. Factors affecting the way students collaborate in a wiki for English language learning [J]. Australasian Journal of Educational Technology, 2009, 25(5):645-665.

[4] Webb S. Can ICT reduce social exclusion? The case of an adults' English language learning programme [J]. British Educational Research Journal, 2006, 32(3):481-507.

[5] Fiona Hyland. Learning Autonomously: Contextualising Out-of-class English Language Learning [J]. Language Awareness, 2004, 13(3):180-202.

[6] RamÍ O, Contreras R. The English Language Learning inside the Escuela Activa Urbana Model in a Public School: A Study of Sixth Graders [J]. Profile, 2008, 9(1):47-62.

[7] Ho C M L. English Language Learning and Technology (review) [J]. Language, 2006, 82(1):191-191.

[8] Bliss S L, Skinner C H, Adams R. Enhancing an English Language Learning Fifth-Grade Student's Sight-Word Reading with a Time-Delay Taped-Words Intervention.[J]. School Psychology Review, 2006, 35:663-670.

[9] Rivers D J. Japanese national identification and English language learning processes [J]. International Journal of Intercultural Relations, 2011, 35(1):111-123.

[10]Riveros M, Alejandra R. Interaction in Online Tutoring Sessions: An Opportunity to Knit English Language Learning in a Blended Program [J]. Profile, 2009, 11(2):117-134.

[11] Ahluwalia, Gupta G, Aggarwal D, et al. The Use of Blogs in English Language Learning: A Study of Student Perceptions [J]. Profile Issues in Teachers Professional Development, 2011, 13(2):29-41.

[12]Engh D. Why Use Music in English Language Learning? A Survey of the Literature [J]. English Language Teaching, 2013, 6(2). 